\title{
¿DEROGACIÓN TÁCITA O INAPLICABILIDAD DE PRECEPTOS LEGALES PRECONSTITUCIONALES?*
}

\author{
¿TACIT DEROGATION OR INAPLICABILITY \\ OF PRE-CONSTITUTIONAL LEGAL PRECEPTS?
}

\author{
Miriam HenríqueZ Viñas ${ }^{* *}$ \\ mhenriqu@uahurtado.cl
}

RESUMEN: El presente trabajo busca establecer si los tribunales de justicia, al decidir el Derecho aplicable, están facultados para declarar derogado un precepto legal preconstitucional por su incompatibilidad con la Constitución, aplicando directamente esta uiltima, como norma jurídica con efectos derogatorios. O si, por el contrario, sólo el Tribunal Constitucional tiene la facultad de verificar la conformidad de la ley con la Constitución, ya por la vía de la acción de inaplicabilidad o de la acción de inconstitucionalidad. Lo anterior, analizando el criterio de la Corte Suprema y del Tribunal Constitucional.

ABSTRACT: This paper wants to establish whether the courts of justice, when deciding the applicable law, may declare a pre-constitutional legal precept derogate for contravening the Constitution, directly applying it as a legal rule with derogating effects. Or, only the Constitutional Court can verify the conformity of the law with the Constitution, through the action of inapplicability or the action of unconstitutionality. The above, analyzing the criteria of the Supreme Court and the Constitutional Court.

PAlabRas CLAVE: Derogación tácita, Inaplicabilidad, Preceptos preconstitucionales, Diálogo jurisdiccional.

KEYWORDS: Tacit derogation, Inaplicability, Pre-constitutional legal precepts, Dialogue between jurisdictions.

\section{INTRODUCCIÓN}

Cada vez que se detecta una antinomia a raíz de la dictación de una nueva Constitución o la reforma de la vigente, surge en nuestro medio la controversia entre la derogación tácita o la inconstitucionalidad sobreviniente de preceptos legales preconstitucionales.

\footnotetext{
* Trabajo recibido el 6 de diciembre de 2016 y aprobado el 3 de mayo de 2017.

** Abogado, Universidad Nacional del Comahue (Argentina). Magíster en Derecho Público, Pontificia Universidad Católica de Chile (Chile). Doctor en Ciencias Jurídicas, Universidad de Santiago de Compostela (España). Profesora de Derecho Constitucional de las Universidad Alberto Hurtado.
} 
Las principales cuestiones que se suscitan son: a) Cuál es el criterio de solución de la incompatibilidad entre normas de distinta jerarquía, siendo la norma superior además posterior, concurriendo en la resolución del conflicto normativo tanto el criterio jerárquico como el cronológico; b) Cuál es el efecto de la aplicación de uno u otro criterio. Esto es, la derogación de la norma legal si se aplica el criterio cronológico; o la inaplicabilidad por inconstitucionalidad o la inconstitucionalidad de la norma legal si se aplica el criterio jerárquico, y c) Lo más debatido -al menos en Chile- cuál es el órgano competente para resolver el conflicto normativo. Se sostiene por algunos que corresponde a los tribunales de justicia declarar la derogación tácita de los preceptos preconstitucionales. Entretanto, otros postulan que la declaración de inaplicabilidad o inconstitucionalidad de la norma legal sólo puede realizarla el Tribunal Constitucional.

El presente artículo pretende concentrarse en la última de las controversias apuntadas, esto es, cuál es el órgano facultado para resolver el conflicto entre la norma legal posiblemente aplicable y decisiva para la resolución de un caso y la norma constitucional posterior. Este debate, si bien es de antigua data, sigue siendo un asunto actualmente controvertido. Recientemente, la Corte Suprema ha dictado una serie de fallos en los que se pronuncia sobre su competencia para declarar derogados tácitamente los preceptos legales preconstitucionales; y al mismo tiempo el Tribunal Constitucional ha dicho lo propio respecto de su competencia exclusiva y excluyente para declarar la inaplicabilidad por inconstitucionalidad de los preceptos legales, ya sean preconstitucionales o posconstitucionales. Todo, sin que sea posible constatar un diálogo entre estas jurisdicciones, intérpretes principales de la Carta Fundamental. Lo complejo, además de la falta de diálogo, es que el sentido de las decisiones de ambas instancias jurisdiccionales puede ser potencialmente contrario. Por ejemplo, el Tribunal Constitucional podría dictar una sentencia desestimatoria de inaplicabilidad de un precepto legal y el juez de la instancia podría declarar ese mismo precepto legal tácitamente derogado.

Para la consecución del objetivo planteado, como esquema de trabajo, propongo analizar los siguientes asuntos: a) Primeramente, buscaré establecer las diferencias entre la declaración de derogación tácita y la declaración de inaplicabilidad sobreviniente del precepto legal preconstitucional, la causa de las antedichas declaraciones, el tipo de control que se ejerce, el órgano competente y sus efectos en el tiempo. Igualmente, analizaré si una declaración puede ser seguida de la otra, es decir, sus conexiones; b) Luego, revisaré a modo ejemplar tres fallos recientes de la Corte Suprema recaídos en acciones de protección, en los que este órgano afirmó su potestad -tanto en el voto de mayoría como en el 
voto disidente- para declarar tácitamente derogado un precepto legal preconstitucional; c) A continuación, analizaré fallos recientes del Tribunal Constitucional recaídos en sede de inaplicabilidad por inconstitucionalidad, en los que este órgano afirmó su potestad para conocer de la inaplicabilidad sobreviniente; d) Por último, a propósito de las conclusiones, buscaré identificar si se ha generado un diálogo entre las jurisdicciones, es decir, entre los razonamientos de la Corte Suprema y del Tribunal Constitucional sobre este asunto.

\section{DifERENCIAS Y CONEXIONES ENTRE LA DECLARACIÓN}

DE DEROGACIÓN TÁCITA Y LA INAPLICABILIDAD SOBREVINIENTE

\section{A. Diferencias y conexiones}

La declaración de derogación tácita de una norma legal anterior que contradice una norma constitucional posterior no es asimilable -en sus presupuestos, efectos y órganos con facultad para resolverla- a la declaración de inaplicabilidad por inconstitucionalidad.

La derogación está relacionada con la vigencia de la norma. El principio que determina la derogación es el cronológico, el cual resuelve verdaderos conflictos normativos diacrónicos entre normas válidas. La derogación es un fenómeno perfectamente regular, cuyo fundamento es responder al cambio en el sistema jurídico, ya sea para sustituir una norma por otra o para eliminar alguna norma perteneciente hasta ese momento al mismo ${ }^{1}$. Corresponde distinguir entre derogación expresa y tácita.

La derogación es un acto normativo, fruto de una decisión política ${ }^{2}$. Así, quien deroga es el órgano con capacidad normativa, quien lo hace con efectos generales y ex nunc. Los efectos señalados corresponden a la derogación expresa. Por su lado, la derogación tácita es aquella que se produce por la incompatibilidad entre normas producidas en distintos momentos temporales. La derogación tácita requiere ser declarada. Tal declaración -generalmente emanada de un tribunal de justicia- importa un acto de interpretación al caso particular y la no aplicación de la norma derogada 3 .

1 Henríquez (2013), p. 303.

2 Guastini (2001), p. 62.

3 A juicio de Bascunán Rodríguez, la derogación tácita se produce cuando el órgano que debe resolver un caso, y debe fundar su decisión sujetándose al derecho vigente, constata que éste contiene dos soluciones 
Por otra parte, el control que se ejerce en virtud de la acción de inaplicabilidad por inconstitucionalidad no es uno estrictamente normativo que pretenda resolver un conflicto entre una inferior y una norma superior, es decir, entre una norma legal y una norma constitucional. El objeto de la acción de inaplicabilidad por inconstitucionalidad es identificar si la posible aplicación de un precepto legal en un caso concreto produce o no efectos contrarios a la Constitución, a fin de evitar el resultado irregular que significaría dicha aplicación al reconocer a la Constitución supremacía normativa.

Tal posible inaplicación por inconstitucionalidad de un precepto legal en un caso concreto debe ser declarada por el Tribunal Constitucional, si ha sido requerido por las partes o el juez de la gestión pendiente, según el artículo 93 No 6 de la Carta Fundamental. Así, la sentencia estimatoria de inaplicabilidad genera en el tribunal de la gestión la obligación de no aplicar el precepto legal a la solución del caso. Para el caso concreto -en palabras de Núñez Poblete- significa que la sentencia de inaplicabilidad "retira" del ordenamiento jurídico el precepto legal que vinculaba positivamente al juez hasta el fallo de inaplicabilidad 4 . En otro artículo, el mismo autor enfatiza: "Sin embargo, el efecto que la sentencia de inaplicabilidad genera para el caso que ella incide es bien distinto de la derogación. En efecto, lo que persigue el fallo constitucional es retirar del ordenamiento jurídico, para el caso especifico de que se trata, el precepto legal declarado inaplicable's.

Respecto a los efectos de la declaración de inaplicabilidad en el tiempo, Zúñiga Urbina agrega que produce efectos retroactivos o ex tunc: "En consecuencia, se trata de una sentencia que a partir de su dictación y notificación, produce efectos constitutivos de una situación jurídica que impide aplicar el precepto legal declarado inaplicable't. En un sentido coincidente sobre los efectos de la sentencia de inaplicabilidad en el tiempo, Núñez Poblete afirma: "En otras palabras, siendo la

distintas para ese caso, incompatibles entre sí. En opinión del mismo autor, la derogación tácita de la ley anterior no es el efecto de un acto realizado en ejercicio de una potestad normativa, sino los efectos de un complejo de reglas que gobiernan el ejercicio de la potestad jurisdiccional. Estas reglas obligan al órgano adjudicador a seleccionar de una manera determinada la norma aplicable al caso. Por tal motivo, la derogación tácita de la ley anterior es constatada y declarada por el tribunal en la fundamentación de su sentencia. Por eso supone un acto interpretativo de la norma anterior y la posterior, que identifique sus respectivos sentidos y constate su incompatibilidad entre sí. BASCUÑán (2000), p. 238.

4 NúNẼz (2012), p. 43.

5 NúNEZ (2011), p. 169.

6 Vega y ZúNiga (2006), p. 155. 
inaplicabilidad algo muy diverso a la derogación legislativa y a la declaración judicial de inconstitucionalidad, no es exacto afirmar que al momento de haberse dictado el acto este se haya ajustado a la legalidad vigente. Muy por el contrario, el fallo de inaplicabilidad obliga a los jueces a juzgar el acto como si nunca hubiera existido una ley habilitante que lo autorizara (...) El sentido de la inaplicabilidad es entonces más cercano al de la inexistencia de la ley que al de su derogación".

Como se advierte, la declaración de derogación tácita significa que el juez no aplicará el precepto legal previo que contradice la norma constitucional posterior al caso concreto, al haber cesado su vigencia. A diferencia de la sentencia estimatoria de inaplicabilidad sobreviniente que excluye la aplicación del precepto legal que devino inconstitucional en un caso concreto, manteniendo dicho precepto legal su vigencia y vocación indefinida de aplicabilidad a otros casos, siendo sus efectos -como se señaló- retroactivos. En ambos casos el efecto es relativo o inter partes. Sólo se producirá un efecto general, con efectos ex nunc, en el evento que se declare la inconstitucionalidad del precepto legal, producto de un control normativo y abstracto de las normas en conflicto, conforme a lo dispuesto en el artículo 93 No 7 de la Constitución. Empero este último efecto significa que la norma impugnada deja de pertenecer al orden jurídico, hacia el futuro, sus efectos no son derogatorios, sino invalidatorios.

Un apresurado análisis nos permitiría concluir que la derogación tácita y la inaplicabilidad sobreviniente de un precepto legal preconstitucional producen el mismo efecto: la inaplicabilidad para el caso concreto. Sin embargo, según lo expuesto, la primera obedece a un fenómeno completamente regular-el cambio en el sistema jurídico- que será declarado por el tribunal de la causa. La segunda, corresponde a una situación irregular que se pretende evitar por una de las partes de la gestión pendiente o por el juez de la causa, siendo declarada así por el Tribunal Constitucional.

Además de lo apuntado, la principal diferencia entre ambas fórmulas radica en que la declaración de derogación tácita de preceptos preconstitucionales es el resultado de un control normativo, entre dos normas incompatibles, siendo una de ellas -la Constitución- norma posterior. Por su parte, la sentencia estimatoria de inaplicabilidad no es el resultado de un control normativo, sino de un control de la aplicación de la norma legal en un caso concreto que produce efectos contrarios a una norma superior, la Constitución.

7 NúNEZ (2011), p. 169. 
Por lo anterior, no existe una conexión estructural entre la derogación tácita de preceptos legales preconstitucionales y la inaplicabilidad sobreviniente. La conexión entre ambas instituciones sólo puede ser fáctica. En tales supuestos las secuencias posibles son: a) A juicio del Tribunal Constitucional, la norma declarada aplicable -en una sentencia desestimatoria de inaplicabilidad- no podría declararse derogada tácitamente por el tribunal de instancia; b) A juicio de la Corte Suprema, si en virtud de una sentencia firme y definitiva, un tribunal no hubiera aplicado una norma legal por haberla estimado derogada tácitamente, dicha norma no podrá ser declarada inaplicable por el Tribunal Constitucional por no existir gestión pendiente. Esto no obsta a que el Tribunal Constitucional en otro caso en que sea aplicable el precepto legal previamente declarado derogado por un tribunal, pueda declararlo inaplicable.

\section{B. las posiciones doctrinarias}

Se ha entendido que la Constitución como fuente del Derecho posee eficacia directa. La eficacia de la Constitución puede ser directa o indirecta. La primera importa la aplicación de la Constitución por todos los órganos llamados a aplicar el orden jurídico, esencialmente los jueces. La eficacia indirecta constituye un mandato al legislador, que sólo afectará a la actividad de los demás órganos del Estado en la medida en que se haya incorporado a las leyes ${ }^{8}$.

La Constitución Política declara expresamente su eficacia directa en el artículo 6, al señalar que los órganos del Estado deben someter su acción a la Constitución y que sus preceptos obligan "tanto a los titulares o integrantes de dichos órganos, como a toda persona, institución o grupo", no siendo necesario el dictado de otras normas, legales o infralegales, que la doten de sustento o eficacia. Uno de los asuntos discutidos de la eficacia directa de la Constitución es si la misma tiene efectos derogatorios respecto de las normas previas o preconstitucionales.

Para cierto sector de la doctrina, entre quienes destaca Zúñiga Urbina, el conflicto entre la norma legal anterior y la norma constitucional posterior se resuelve mediante la declaración de inaplicabilidad o inconstitucionalidad de la norma legal por aplicación del criterio jerárquico, siendo competente sólo el Tribunal Constitucional ${ }^{9}$.

8 Henríquez (2016), p. 31.

9 Francisco Zúñiga y Francisco Vega señalan que la solución de la derogación tácita de los preceptos preconstitucionales introduciría "el germen de un modelo difuso de Jurisdicción Constitucional, inconciliable 
Entretanto, otros autores como Cordero Quinzacara, Aldunate Lizana y Rojas Chamaca postulan la posibilidad de que los tribunales declaren la derogación tácita de los preceptos preconstitucionales.

En tal sentido, Cordero Quinzacara expresa la procedencia de la declaración de derogación tácita de los preceptos legales preconstitucionales por los tribunales de justicia; y la declaración de inaplicabilidad de los preceptos legales posconstitucionales por el Tribunal Constitucional: "Asi, si la norma es previa y ha devenido en inconstitucional, es claro que la solución será la derogación de la misma, cuya declaración corresponde a todo órgano llamado a aplicar el derecho, como son los jueces de la instancia, en la medida que constatan una consecuencia jurídica que ya se ha producido. En cambio, si la norma es postconstitucional esta posibilidad se ve fuertemente restringida, en la medida que la competencia al efecto queda radicada en el Tribunal Constitucional, tanto para constatar la derogación como para inaplicar la norma legal o anularla, en su caso"10.

Las razones que expone Rojas Chamaca para sostener la tesis de la derogación tácita de los preceptos preconstitucionales por la jurisdicción ordinaria son principalmente las siguientes: a) Procede la aplicación del criterio cronológico por sobre el criterio jerárquico, aun cuando ambos son concurrentes para la solución de este tipo de antinomia; b) La necesaria distinción entre la vigencia y la validez de las normas. Así, a juicio del autor, la norma legal anterior debe ser declarada derogada -no inválida- si contradice materialmente la norma constitucional posterior, pues la primera era vigente y válida antes del cambio constitucional. La derogación tácita sería la cesación de la vigencia de la norma legal anterior. La invalidez, entonces, no puede ser sobreviniente; c) La fuerza normativa de la Constitución obliga a todos los órganos del Estado, incluidos los tribunales ordinarios de justicia, a cumplir y aplicar directamente la Carta Fundamental, y d) La consideración de la Constitución como una norma jurídica que, como cualquiera otra, tiene la capacidad de derogar normas jurídicas anteriores de igual o inferior rango que la contradigan ${ }^{11}$.

Por su parte, Aldunate Lizana explica enfáticamente, a propósito de la fuerza normativa de la Constitución, la facultad de los jueces para decidir el Derecho

con la concentración y monopolio del control de constitucionalidad conferido al Tribunal Constitucional por la reforma constitucional de 2005.” Zúníiga y VeGA (2006), pp. 158 y 159.

10 Cordero (2009), p. 27.

11 Rojas (2012), pp. 157-162. 
aplicable y la necesidad de considerar en tal operación todo el sistema de fuentes, incluido la Constitución. En tal contexto, el autor estima que los jueces pueden declarar tácitamente derogado un precepto legal preconstitucional: "No se observa una razón para afirmar que el mismo juez que puede resolver la antinomia en el caso de derogación tácita no puede realizar la misma operación cuando la misma antinomia opera respecto de la misma Constitución, sólo que respecto de un precepto posterior a la entrada en vigencia de la misma. El argumento que señala que ello se debe al sistema de concentración de control de constitucionalidad en el Tribunal Constitucional pasa por alto que esta magistratura no resuelve, para la respectiva gestión judicial, la antinomia entre Constitución y precepto legal, sino que la elimina, al retirar del universo de fuentes que deberá considerar el juez del fondo, al resolver, el precepto legal cuya aplicación se impugna por inconstitucional. De este modo no se le ha otorgado al Tribunal Constitucional la facultad de resolver estas antinomias y mal podría sostenerse entonces que a los jueces del fondo carecen de una atribución, porque ésta se alega entregada al Tribunal, cuando efectivamente no se le ha entregado. Esta solución es precisamente el argumento que tiende a reforzar la idea de que el predicado de fuerza normativa de la constitución como eficacia directa incluye al derecho constitucional en el sistema de fuentes que debe considerar y resolver cualquier juez, de acuerdo a la idea de control difuso examinada arriba"12.

A mi juicio, se derivan una serie de consecuencias del hecho que la Constitución sea fuente del Derecho con eficacia directa y que su garantía jurisdiccional se encuentre, desde la reforma constitucional de 2005, concentrada en el Tribunal Constitucional: a) La primera, los tribunales de justicia, al decidir el Derecho aplicable, tienen la facultad de declarar derogado un precepto legal preconstitucional por su incompatibilidad con la Constitución, aplicando directamente la norma constitucional posterior. Se trataría éste de un problema de vigencia de normas resoluble mediante la aplicación del criterio cronológico; b) La segunda, el Tribunal Constitucional está facultado para verificar la conformidad del precepto legal posconstitucional con la norma constitucional superior, ya por la vía de la acción de inaplicabilidad o de la acción de inconstitucionalidad, siendo esta una cuestión de aplicabilidad/validez/constitucionalidad de normas resoluble conforme al criterio jerárquico, más particularmente de la supremacía constitucional; c) En ambos supuestos, la norma aplicable con preferencia a la otra es la norma constitucional posterior y superior; d) Los tribunales de justicia

12 Aldunate (2009), p. 455. 
carecen de la potestad para declarar la inaplicabilidad de las normas legales pre y posconstitucionales que contravienen la Constitución. En un sistema de control concentrado de constitucionalidad como el chileno la declaración de inaplicabilidad por inconstitucionalidad o de inconstitucionalidad sólo le corresponde al Tribunal Constitucional, y e) Nada obsta a que las partes o el juez de la gestión pendiente requieran al Tribunal Constitucional para que declare la inaplicabilidad por inconstitucionalidad de un precepto legal preconstitucional, aplicable y decisivo en un caso concreto.

\section{La(s) tesis de la Corte Suprema y la derogación tácita DE PRECEPTOS CONSTITUCIONALES EN FALLOS RECIENTES}

La Corte Suprema, a partir de la reforma constitucional de 2005, ha dictado una serie de fallos en los que reconoce su facultad, y la de los demás tribunales de justicia, para declarar tácitamente derogados los preceptos legales preconstitucionales. Las sentencias que constituyen un hito en la materia son las causas Roles Nos. 5420-2008, 1018-2009, 800-2009 y 6552-2009 ${ }^{13}$, todas dictadas por el máximo tribunal.

Sin embargo, recientemente, la Corte Suprema dictó tres sentencias que renuevan el debate. Se trata de las causas Roles $\mathrm{No}^{\circ}$. 35236-2016 14 , 43367-201615 y 44989-201616. En un lapso inferior a dos meses el superior tribunal sentó dos tesis: a) La primera, sostiene que los tribunales ordinarios, en el ejercicio de su facultad de decidir el Derecho aplicable y por aplicación directa de la Constitución, tienen competencia para declarar tácitamente derogados los preceptos legales anteriores a la Constitución; b) La segunda, contraria a la anterior, resuelve que sólo el Tribunal Constitucional está facultado para declarar la inaplicabilidad por inconstitucionalidad de un precepto legal preconstitucional.

Los tres casos versan sobre ciudadanos extranjeros que solicitaron hora para contraer matrimonio en la oficina del Registro Civil, la que fue denegada por la autoridad por no contar uno de los contrayentes con cédula de identidad para extranjeros, el que no pudo obtenerse por registrar pendiente un decreto de ex-

13 Jurisprudencia referida por ROJAS (2012), pp. 86-102.

14 Corte Suprema. Rol No 35236-2016, 30 de agosto de 2016.

15 Corte Suprema. Rol No 43367-2016, 6 de octubre de 2016.

16 Corte Suprema. Rol No 44989-2016, 6 de octubre de 2016. 
pulsión del país. En todos ellos, los recurrentes dedujeron acción de protección invocando la afectación al derecho a la igualdad ante la ley y que la conducta de la autoridad administrativa representaba una discriminación arbitraria.

La autoridad recurrida, el Servicio de Registro Civil e Identificación, arguyó que su actuación era legal por cuanto procedió con apego a lo dispuesto en el artículo 76 del Decreto Ley No 1.094 de 1975, que dispone: "Los servicios y organismos del Estado o Municipales deberán exigir a los extranjeros que tramiten ante ellos asuntos de la competencia de esos servicios, que previamente comprueben su residencia legal en el país y que están autorizados o habilitados para realizar el correspondiente acto o contrato"; el artículo 92 del Reglamento Orgánico del mencionado Servicio; la circular No 5/1996; y el Dictamen de la Contraloría General de la República No 6.197/1998, que solamente excluye de aplicación la norma legal en comento para la inscripción de nacimientos.

La Tercera Sala de la Corte Suprema ${ }^{17}$, en el primer fallo de agosto de 2016, Rol No 35236-2016, acogió el recurso de protección, revocó la sentencia apelada y afirmó su competencia -y la de los tribunales de justicia- para declarar derogado el artículo 76 del Decreto Ley No 1.094.

Por su parte, la misma sala de la Corte Suprema, pero con una integración distinta a la anterior ${ }^{18}$, en el mes de octubre de 2016, confirmó la sentencia apelada, rechazó la acción de protección y negó tener atribuida la competencia para declarar derogado el mentado artículo 76, dando a entender que la declaración de inaplicabilidad sobreviniente corresponde al Tribunal Constitucional. Empero, en ambas sentencias, el voto disidente reiteró el razonamiento plasmado en el fallo de agosto del mismo año.

Las razones invocadas por la Corte Suprema, en el fallo Rol No 35236-2016, para declarar tácitamente derogado el mencionado artículo 76 se plasmaron en un extenso considerando sexto y son fundamentalmente las siguientes: a) La diferencia entre validez-constitucionalidad y vigencia de una norma legal, siendo competencia de los tribunales de justicia resolver sobre esta última por aplicación directa de la Constitución. En palabras de la Corte, los tribunales ordinarios: "tie-

17 En este caso, la Corte Suprema estuvo integrada por los Ministros Sergio Muñoz, Rosa Egnem, María Eugenia Sandoval, Carlos Aránguiz y el Abogado Integrante Jorge Lagos. La decisión fue acordada con el voto en contra de las Ministras Rosa Engmen y María Eugenia Sandoval.

18 En estos casos, la Corte Suprema estuvo integrada por los Ministros Rosa Egnem, María Eugenia Sandoval, Carlos Aránguiz, Manuel Valderrama y el Abogado Integrante Rafael Gómez. La decisión fue acordada con el voto en contra de los Ministros Carlos Aránguiz y Manuel Valderrama. 
nen competencia para definir la vigencia de un precepto legal, puesto que tratándose de una norma constitucional posterior pueden recurrir al criterio temporal para resolverlo, conforme al principio que ante una antinomia o contradicción entre normas jurídicas "ley posterior deroga ley priori" (sic), circunstancia que los tratadistas refuerzan en el caso de las normas constitucionales posteriores, pues se conjugan, además, los principios jerárquico, suprema (sic) constitucional y aplicación directa de la constitución al caso"; b) La diferencia entre la declaración de inaplicabilidad por inconstitucionalidad o la declaración de inconstitucionalidad, por un lado; y la declaración de derogación tácita, por el otro; como efectos de la aplicación del criterio jerárquico y cronológico respectivamente; y los órganos facultados para ello. La declaración de inaplicabilidad o inconstitucionalidad le correspondería al Tribunal Constitucionalidad, mientras que los tribunales ordinarios podrían declarar derogado un precepto legal anterior a la Constitución al determinar el Derecho aplicable al caso: "Queda así diferenciada la facultad que permite a todo juez considerar derogada una norma legal por ser contraria a la Constitución y la que se radica en el Tribunal Constitucional que le otorga competencia para declarar su inaplicabilidad o inconstitucionalidad"; c) La inexistencia, tras la reforma constitucional de 2005, de una norma que excluya el control de leyes preconstitucionales de la competencia de los tribunales ordinarios: "Luego de seguir una discusión sobre el particular y de recibir versadas opiniones no se reguló expresamente el punto, por lo cual no se excluyó de la competencia de los tribunales ordinarios, la facultad de resolver sobre la derogación de los preceptos legales al constar la contradicción expresa de normas legales pretéritas respecto de una norma constitucional posterior", y d) La cita a ciertos autores, nacionales y extranjeros, que avalarían su postura, tales como Silva Bascuñán, Precht Pizarro, Silva Cimma, Cea Egaña, Bulnes Aldunate, de Otto, Díez-Picazo, así como la mención a la jurisprudencia del Tribunal Constitucional español.

En un sentido contrario, los fallos de 6 de octubre de 2016 resolvieron que, atendida la situación migratoria de los accionantes, la actuación del servicio no es ilegal ni arbitraria y tampoco supone una discriminación caprichosa que pueda afectar el derecho a la igualdad ante la ley.

La incompetencia de la Corte Suprema -y de los tribunales de justicia en general- para declarar la derogación tácita del artículo 76 del Decreto Ley No 1.094 se deduce de los considerandos sexto y quinto de las causas Rol No 43367-2016 y Rol No 44.989-2016, que señalan respectivamente: "Que en estos autos los recurrentes no han planteado ante el Tribunal Constitucional la inaplicabilidad del artículo 76 del D.L. No 1.094, cuestión que tampoco han efectuado los tribunales que han conocido de este recurso". 
La afirmación anterior puede deducirse de la referencia a la competencia del Tribunal Constitucional para declarar la inaplicabilidad de los preceptos legales, de conformidad con el numeral 6 del artículo 93, así como la mención de que en el caso no se planteó por la parte o por el tribunal una acción de inaplicabilidad.

\section{LA(s) TESIS DEL TRIBUNAL CONSTITUCIONAL SOBRE LA INAPLICABILIDAD SOBREVINIENTE DESDE LA REFORMA CONSTITUCIONAL DE 2005}

La primera oportunidad, luego de la reforma constitucional de 2005, que el Tribunal Constitucional afirmó su competencia para conocer de la acción de inaplicabilidad respecto de un precepto legal preconstitucional fue en la sentencia Rol No $472^{19}$. Se trató de un requerimiento deducido por Rafael Celume Sacaan, por el cual se solicitó la inaplicabilidad del artículo 116 del Código Tributario, en la instancia abierta con la interposición del recurso de apelación ante la Corte de Apelaciones de Santiago, Rol No 4985-2002.

La solución jurídica que brindó el Tribunal Constitucional en su sentencia se expresó en el considerando séptimo, que señaló: "Que, respecto de la primera alegación, debe tenerse presente que del texto del artículo $93 N^{\circ} 6$ como del inciso undécimo de esa misma norma se desprende, inequivocamente, que la exigencia para que proceda un acción de inaplicabilidad por inconstitucionalidad se refiere a que exista 'un precepto legal' cuya aplicación en cualquier gestión que se siga ante un tribunal ordinario o especial, resulte contraria a la Constitución, de lo cual se infiere que debe tratarse de un precepto legal que se encuentre vigente, con independencia de si dicha vigencia se produjo antes o después que la de la Carta Fundamental. Esta interpretación resulta ser la única que se concilia con el principio de supremacía constitucional consagrado en el artículo $6^{\circ}$, inciso primero de nuestro Código Político. Por lo demás, la conclusión precedente resulta concordante con lo expresado por la Corte Suprema, en diversos fallos, cuando conociendo de requerimientos como los de la especie, ha afirmado que "lo esencial para que esta Corte pueda pronunciarse sobre la inaplicabilidad de una ley radica en la condición de que ésta y la Carta Fundamental se hallen vigentes".

Tal postura fue reiterada en la sentencia Rol No 784 de 2007. En este requerimiento planteado por Patricio Cereceda, se solicitó la declaración de inaplicabilidad del artículo 509 del Código de Procedimiento Penal, en los autos de la Corte Suprema, Rol No 2-2007, caratulados "Roberto Mercado Olguín y otros" sobre

19 Tribunal Constitucional. Rol No 472, de 30 de agosto de 2006. 
recurso de casación en la forma interpuesto por el requirente contra la sentencia de segunda instancia dictada por la Corte Marcial, autos Rol No 110-2006, que confirmó la sentencia de primera instancia, dictada en autos Rol No 310-2005, del Tercer Juzgado Militar de Valdivia ${ }^{20}$.

Nuevamente el Tribunal Constitucional afirmó su competencia y razonó invocando la jurisprudencia sentada en el anteriormente analizado Rol No 472, señalando en el considerando décimo tercero: "Que, a mayor abundamiento, resulta necesario recordar que este Tribunal, en forma congruente con lo manifestado por la Excma. Corte Suprema, durante el último periodo en que resolvió las acciones de inaplicabilidad por inconstitucionalidad de la ley, ha precisado que la exigencia para que proceda un acción de inaplicabilidad por inconstitucionalidad se refiere a que exista un 'precepto legal' cuya aplicación en cualquier gestión que se siga ante un tribunal ordinario o especial resulte contraria a la Constitución, de lo cual se infiere que debe tratarse de un precepto legal que se encuentre vigente, con independencia de si dicha vigencia se produjo antes o después que la de la Carta Fundamental'. (Sentencia Rol No 472, de 30 de agosto de 2006, considerando séptimo)".

En los dos casos referidos, el Tribunal Constitucional estimó que: a) La acción de inaplicabilidad procede sólo respecto de preceptos legales vigentes; b) Que su competencia para conocer de la acción de inaplicabilidad lo es tanto de preceptos legales vigentes con anterioridad o posterioridad a la entrada en vigencia de la Constitución Política; c) Lo anterior por aplicación del criterio jerárquico, más precisamente por aplicación del principio de supremacía constitucional; y d) Su competencia se funda incluso en el recurso de inaplicabilidad del que conocía la Corte Suprema, previo a la reforma de 2005.

Luego, a partir de la sentencia Rol No 991 de 2009, el Tribunal Constitucional modificó su tesis de la exigencia del precepto legal "vigente" por aquella que requiere que el precepto legal sea "aplicable". En el referido requerimiento, deducido por Fernando Valenzuela, se solicitó declarar inaplicables los artículos 2o, 11, 15, 16, 19, 26 y 29 del Decreto Ley No 2.695, de 1979, que fija normas para regularizar la posesión de la pequeña propiedad raíz y para la constitución del dominio sobre ella, en los autos sobre juicio ordinario de nulidad caratulados "Baltierra con Guerrero", Rol No 19620, del Juzgado de Letras de Curepto, tramitándose al momento de la interposición ante la Corte Suprema, bajo el Rol No 5917-2006, y que corresponde al recurso de casación en el fondo interpuesto

20 Tribunal Constitucional. Rol No 784, de 20 de diciembre de 2007. 
en contra de la sentencia de segunda instancia dictada por la Corte de Apelaciones de Talca ${ }^{21}$.

Como cuestión previa el Tribunal Constitucional se pronunció sobre su competencia, con rasgos de insustituible, para conocer de la constitucionalidad de un precepto legal derogado. Señaló: “(...) Para desechar esta alegación basta recordar la doctrina permanente del Tribunal Constitucional, conforme a la cual el mismo ha sostenido que, aunque la entrada en vigencia de un precepto legal sea anterior a la de la norma constitucional con la que resultaría contraria en su aplicación judicial, ello no es obstáculo para su impugnación por la vía de la acción de inaplicabilidad. Este medio de control de constitucionalidad tiene por objeto evitar la aplicación en una gestión judicial que se sigue ante un tribunal ordinario o especial de uno o más preceptos legales que eventualmente puedan recibir aplicación y produzcan, en tal caso, efectos contrarios a la Constitución, para lo cual la intervención de esta Magistratura es insustituible. En efecto, si el Tribunal Constitucional se inhibiera de actuar porque en la gestión judicial en que incide el requerimiento se ha planteado la derogación tácita de los preceptos legales cuya inaplicabilidad se ha solicitado, bien pudiera ocurrir que, en definitiva, el tribunal de la causa los estimara vigentes, con lo que se eludiria la decisión, que es propia de esta Magistratura Constitucional, en torno a la aplicación conforme o contraria con la Constitución de un precepto legal". (Considerando quinto).

Como puede apreciarse, el Tribunal Constitucional mantuvo el criterio sentado en la sentencia Rol No 472, en cuanto a que tiene competencia para conocer de la constitucionalidad de la aplicación de los preceptos legales vigentes antes o después de la entrada en vigencia de la Constitución Política. Sin embargo, dejó de mencionar que el precepto impugnado debe estar "vigente" para que proceda conocer de la acción de inaplicabilidad y enfatizó que el mismo debe ser "aplicable". El cambio de sentido parece acertado, toda vez que no es necesario que el precepto legal se encuentre vigente para ser declarado inaplicable, porque es posible que el precepto legal esté derogado y sin embargo sea aplicable por el juez de la gestión, atendida su ultraactividad. Esta posición se reiteró en las sentencias Roles $\mathrm{No}^{\circ} .1399$ y 1469 acumuladas de $2009^{22}$.

En 2013, se dictó la sentencia Rol No 2341, que resolvió acoger la acción de inaplicabilidad por inconstitucionalidad deducida por Alejandro Fainé Maturana,

21 Tribunal Constitucional. Rol No 991, de 29 de enero de 2009.

22 Tribunal Constitucional. Roles Nos. 1399 y 1469 acumuladas, de 4 de noviembre de 2010. 
quien impugnó el inciso cuarto del artículo $8^{\circ}$ de la Ley No 19.640, Orgánica Constitucional del Ministerio Público y vigente desde 1999, en el marco de un reclamo de ilegalidad regido por el artículo 9º, inciso tercero, de la Ley No 20.285, en consideración a que su aplicación afecta el artículo $8^{\circ}$, inciso segundo, de la Constitución Política, incorporado por reforma constitucional de $2005^{23}$.

El Tribunal Constitucional afirmó en el considerando séptimo su competencia exclusiva para declarar la inconstitucionalidad sobreviniente y que no se trata de un caso de derogación tácita, pues ésta última sólo ocurre entre normas de la misma jerarquía: "Que, a diferencia de lo argumentado precedentemente, esta Magistratura estima que el precepto impugnado si tiene una influencia decisiva para la resolución de la gestión pendiente, toda vez que la parte de la norma que contiene la expresión "o reglamentarias" no está derogada, sino que adolece de una inconstitucionalidad sobreviniente o sobrevenida por haber entrado en contradicción con el artículo $8^{\circ}$ de la Constitución. En efecto, no se está en presencia de una derogación, debido a que ésta sólo puede operar entre normas de igual jerarquía normativa. En definitiva, hay que tener presente que si bien una derogación puede ser constatada y declarada por el juez del fondo, cuando se está ante una inconstitucionalidad sobrevenida la competencia exclusiva corresponde al juez constitucional".

En el año 2014, el Tribunal Constitucional dictó la sentencia Rol No 2647 en virtud de la acción deducida por el abogado José Luis Zavala, quien solicitó la declaración de inaplicabilidad por inconstitucionalidad de los artículos 15 y 16 del Decreto Ley No 2.695, de 21 de julio de 1979, que fija normas para regularizar la posesión de la pequeña propiedad raíz y para la constitución del dominio sobre ella, para que surta efectos en el juicio ordinario sobre cancelación material de inscripciones "Forestal Mininco con Reyes González, Carlos y otros", por estimar que su aplicación infringe lo dispuesto en el numeral $24^{\circ}$ del artículo 19 de la Carta Fundamental y las garantías de igualdad ante la ley, del debido proceso y de no afectación de los derechos en su esencia, previstas en los numerales $2^{\circ}, 3^{\circ}$ y 26, del referido artículo ${ }^{24}$.

En el presente caso, no se alcanzó el quórum exigido por la Carta Fundamental para acoger el requerimiento, resolviéndose el rechazo del mismo. Sin embargo, los fundamentos del voto que estuvo por rechazar el requerimiento revisten total interés, toda vez que se pronuncian sobre la facultad del Tribunal Constitucional

23 Tribunal Constitucional. Rol No 2341, de 14 de agosto de 2013.

24 Tribunal Constitucional. Rol No 2647, de 23 de diciembre de 2014. 
para declarar con carácter exclusivo la inconstitucionalidad sobreviniente ${ }^{25}$, con razones semejantes a las recientemente expuestas en la II Jornada de reflexión del Tribunal Constitucional "Inconstitucionalidad sobrevenida/derogación tácita ¿control difuso o concentrado?”, llevada a cabo el 2 de noviembre de $2016^{26}$.

Del referido voto de rechazo, puede destacarse: a) La afirmación del Tribunal Constitucional sobre su competencia exclusiva para declarar la derogación con efectos generales y ex nunc de un precepto legal inconstitucional, en contraposición al efecto relativo de la declaración de derogación tácita resuelta por un juez: "Por el contrario, sólo el Tribunal Constitucional puede derogar por sentencia firme, ex nunc, un precepto legal, con efecto general o erga omnes y siempre que previamente se hubiere declarado inaplicable, tal como establece el artículo 93, $N^{\circ} 7^{\circ}$, de la Constitución, en relación al artículo 94, inciso tercero, parte final, de la Carta Fundamental, que en lo pertinente dispone que...". No obstante, el precepto declarado inconstitucional en conformidad a lo dispuesto en los numerales... 7 del artículo 93, se entenderá derogado desde la publicación en el Diario Oficial de la sentencia que acoja el reclamo, la que no producirá efecto retroactivo. "Por ende, sólo el Tribunal Constitucional puede producir un efecto derogatorio general por razones constitucionales. Si, a su vez, la Corte Suprema divisa una situación de derogación tácita por inconstitucionalidad sobreviniente, y asi lo declara judicialmente en sede ordinaria, tal pronunciamiento sería meramente declarativo o de certeza sobre un efecto que habría producido la Constitución misma, pero no por ello esa sentencia de mera certeza tendrá efectos generales, según se ha puntualizado" (considerando $12^{\circ}$ ); b) Que la norma declarada aplicable por el Tribunal Constitucional no puede ser luego declarada derogada tácitamente por el tribunal de la causa: "Por cierto, si esta Magistratura Constitucional declarase en consecuencia la inaplicabilidad de un precepto legal, la Corte Suprema no podría por su parte aplicarlo, sin quebrantar los equilibrios institucionales. Lo que también vale al revés, toda vez que el problema más complejo ha venido planteándose en la hipótesis inversa, esto es, cuando esta Magistratura Constitucional desecha la inaplicabilidad concreta por inconstitucionalidad y, no obstante ello, la Corte Suprema podría adoptar su propio pronunciamiento de inconstitucionalidad, invocando criterios de derogación tácita u orgánica de indole constitucional sobreviniente, con lo cual, oblicuamente, lograría una pseudo inaplicabilidad del precepto legal, por la vía

25 El voto por rechazar el requerimiento correspondió a los Ministros Carlos Carmona, Marisol Peña, Gonzalo García y Domingo Hernández.

26 Ver en http://www.tribunalconstitucional.cl/wp/wp-content/uploads/Conclusiones-II-Jornada-deReflexi\%C3\%B3n-TC.pdf, consultado el 30 de noviembre de 2016. 
consecuencial de la expulsión del precepto legal del ordenamiento jurídico, en tanto derogado, pese a lo resuelto previamente por el Tribunal Constitucional en el sentido de no existir antinomia o incompatibilidad constitucional" (considerando 13o); y c) Su competencia exclusiva para ejercer el control entre normas de distinta jerarquía, por aplicación del principio de supremacía constitucional, desde que ostenta el control concentrado de constitucionalidad de las normas, en virtud de la reforma constitucional de 2005: "Sin embargo, en la institucionalidad chilena, el concepto de control concentrado de constitucionalidad radicado en el Tribunal Constitucional es categórico. $Y$ así, por lo demás, ha sido resuelto en esta sede incluso respecto de leyes preconstitucionales. Este Tribunal Constitucional, por su parte, ha tenido oportunidad de expresar que: la discrepancia entre preceptos de distinta jerarquía -una ley y la Constitución - constituye una cuestión de supremacía constitucional que debe ser resuelta por esta Magistratura' (c. $8^{\circ}$ de sentencia Rol 943, de 10 de junio de 2008, en línea con lo señalado en Roles 472, c. $7^{\circ}$, y 499, c. $7^{\circ}$ )" (considerando 15\%).

Como puede apreciarse, las tesis del Tribunal Constitucional, a propósito de su competencia para declarar la inaplicabilidad e inconstitucionalidad sobreviniente, son las siguientes: a) Primera, el Tribunal Constitucional puede declarar la inaplicabilidad por inconstitucionalidad respecto de un precepto legal que se encuentre vigente, con independencia de si dicha vigencia se produjo antes o después que la de la Carta Fundamental; b) Segunda, que supone el abandono de la tesis anterior, el Tribunal Constitucional puede declarar la inaplicabilidad por inconstitucionalidad respecto de un precepto legal que se encuentre vigente o derogado, puesto que lo relevante es que sea "aplicable" en un caso concreto; c) Tercera, el Tribunal Constitucional tiene atribuciones exclusivas, excluyentes e insustituibles para declarar inaplicable e inconstitucional un precepto legal, sin distinguir si éste es previo o posterior a la Constitución o sus reformas, de conformidad con lo dispuesto en el artículo $93 \mathrm{No}^{\circ}$. 6 y 7 de la Constitución. Esto, en virtud del principio de competencia y el modelo de control concentrado de constitucionalidad; d) Cuarta, la vinculación directa de los jueces a la Constitución, de conformidad con el artículo $6^{\circ}$ de la Constitución, supone que si un juez estima que el precepto legal aplicable no se conforma a la Carta Fundamental, está obligado a plantear la cuestión ante el Tribunal Constitucional; e) Quinta, los preceptos legales preexistentes que contravienen la nueva Constitución o sus reformas generan un problema de inconstitucionalidad sobreviniente, cuya resolución compete al Tribunal Constitucional, por aplicación del criterio jerárquico o más precisamente del principio de supremacía constitucional. La derogación tácita sólo procede entre normas de la misma jerarquía, y f) Finalmente, el único 
mecanismo derogatorio de leyes que la Constitución dispone se contempla en los artículos 93 No 7 y 94 inciso tercero.

Sobre la última tesis, corresponde decir que el Tribunal Constitucional confunde el efecto invalidatorio de la sentencia que declara la inconstitucionalidad de un precepto legal y su proyección en el tiempo, cuando señala que el único mecanismo derogatorio de las leyes se produce a propósito de la sentencia estimatoria de inconstitucionalidad. Si se reconoce que la sentencia estimatoria supone que la norma impugnada deja de pertenecer al orden jurídico hacia el futuro, sus efectos no son derogatorios, sino invalidatorios ${ }^{27}$.

\section{CONCLUSIONES}

No es posible evidenciar un diálogo horizontal, entendido como una suma de espacios de interlocución, entre los intérpretes constitucionales: Tribunal Constitucional y Corte Suprema. Por el contrario, es notable la divergencia entre tales órganos sobre la vigencia o validez de los preceptos legales preconstitucionales, confrontando la derogación tácita versus la inaplicabilidad sobreviniente. Así:

1. La Corte Suprema expresa que, al decidir el Derecho aplicable, debe considerar a la Constitución como fuente del Derecho directamente aplicable y con efectos derogatorios respecto de los preceptos legales previos. En tal sentido, los tribunales de justicia tienen la facultad de resolver sobre la vigencia de las normas, sobre su aplicación y, por ende, podrán declarar derogados tácitamente aquellos preceptos que contradicen la norma constitucional posterior, sin que ello suponga ejercer un control de constitucionalidad. En un sentido contrario, el Tribunal

\footnotetext{
27 En un sentido coincidente con el expresado, es decir de la invalidez, Sergio Verdugo concluye: "Resulta evidente que -a raíz de lo expuesto- la naturaleza de la declaración de inconstitucionalidad no es la de ser una derogación de las leyes. En realidad, la sentencia derogatoria es un acto de nulidad de Derecho Público atenuada en sus efectos". Verdugo (2008), p. 253.

Así también lo reconoce Humberto Nogueira cuando analiza los efectos de la sentencia de inconstitucionalidad: "En esta materia cabe comentar que la Carta Fundamental utiliza una expresión jurídica 'derogado' que no es propia de un órgano jurisdiccional sino de un órgano legislativo, y de los efectos de la sucesión en el tiempo de las normas legislativas; en el ámbito de los órganos de jurisdicción constitucional la denominación jurídico-técnica correcta es la de nulidad. La nulidad produce la expulsión del precepto del ordenamiento jurídico. Así, para efectos jurídico-técnicos derogación equivale a nulidad, la que produce efectos desde que la sentencia se publica in extenso en el Diario Oficial”. NogueIra (2010), p. 91.

Igualmente, Emilio Garrote reconoce efecto invalidatorio a la sentencia de inconstitucionalidad y dice: "Opera como una sanción depuradora del ordenamiento jurídico. Dado que, la norma declarada inconstitucional es invalidada. Ésta dejará de formar parte del ordenamiento jurídico nacional. Lo que no es más que una consecuencia de lo dispuesto en el inciso final del artículo 7o de la Constitución”. GARROTE (2012), p. 419.
} 
Constitucional afirma tener atribuciones exclusivas, excluyentes e insustituibles para declarar inaplicable e inconstitucional un precepto legal, sin distinguir si éste es previo o posterior a la Constitución o sus reformas, de conformidad con lo dispuesto en el artículo $93 \mathrm{No}^{\circ}$ s 6 y 7 de la Constitución. Esto, en virtud del principio de competencia, supremacía constitucional y el modelo de control concentrado de constitucionalidad.

2. La Corte Suprema estima que, en virtud de la vinculación directa de los jueces a la Constitución, de conformidad con el artículo $6^{\circ}$ de la Constitución, estos pueden declarar tácitamente derogados los preceptos legales preconstitucionales. El Tribunal Constitucional afirma, en virtud de la misma noción de vinculación directa de los jueces a la Constitución, que si un juez considera que el precepto legal aplicable no se conforma a la Carta Fundamental, está obligado a plantear la cuestión ante el Tribunal Constitucional.

3. La Corte Suprema sostiene que los preceptos legales preexistentes que contravienen la nueva Constitución o sus reformas generan un problema de vigencia, que se resuelve por la aplicación del criterio cronológico, que los faculta para resolver la derogación tácita, con efectos particulares para el caso concreto. El Tribunal Constitucional afirma que los preceptos legales preexistentes que contravienen la nueva Constitución o sus reformas generan un problema de validez y constitucionalidad, cuya resolución compete exclusivamente al Tribunal Constitucional, por aplicación del criterio jerárquico o más precisamente del principio de supremacía constitucional. La declaración de inaplicabilidad producirá efectos particulares ex tunc para el caso concreto, mientras que la declaración de inconstitucionalidad -a juicio del Tribunal Constitucional- tendría efectos derogatorios generales ex nunc.

4. La Corte Suprema afirma que la derogación tácita procede entre normas de igual o distinta jerarquía, por ejemplo, entre normas legales y normas constitucionales. El Tribunal Constitucional expone que la derogación tácita procede entre normas de igual jerarquía, no siendo procedente entre normas legales y normas constitucionales.

5. La Corte Suprema expresa que la reforma constitucional de 2005 no excluyó el control de leyes preconstitucionales de la competencia de los tribunales ordinarios. El Tribunal Constitucional expone que la reforma constitucional de 2005 concentró en él, de forma exclusiva y excluyente, el control de constitucionalidad de los preceptos legales pre y posconstitucionales.

Como se advierte, no existe un diálogo entre ambas jurisdicciones. Lo complejo, además de la falta de sincronía entre los principales intérpretes de la Constitución, son 
los sentidos contrarios de sus decisiones, que se evidencian, por ejemplo, cuando la Corte Suprema ha declarado tácitamente derogado los artículos 14 y 15 del Decreto Ley No 2.695 por su contravención con el artículo 19 No 24 de la Constitución (Rol No 800-2009) y la sentencia desestimatoria de inaplicabilidad del Tribunal Constitucional respecto de los mismos preceptos legales (Rol No 2647-2014), que permite al juez de la gestión fallar aplicando el precepto legal cuestionado, con la consiguiente merma a los principios de seguridad jurídica e igualdad ante la ley, bienes básicos de un Estado Constitucional de Derecho.

\section{BiBLIOGRAFÍA}

\section{Doctrina}

Aguiló Regla, Josep (1992): “Derogación, rechazo y sistema jurídico", en Doxa, (11), pp. 263-280.

Alchourrón, Carlos, Bulygin, Eugenio (1991): "Análisis lógico y derecho" (Centro de Estudios Constitucionales, Madrid).

Aldunate Lizana, Eduardo (2009): "La fuerza normativa de la Constitución y el sistema de fuentes del derecho", en Revista de Derecho de la Pontificia Universidad Católica de Valparaíso, XXXII, pp. 443-484.

Bascuñán Rodríguez, Antonio (2000): "Sobre la distinción entre derogación expresa y derogación tácita”, en Anuario de Filosofía Jurídica y Social. Derecho y Cambios Culturales, Vol. 18, pp. 227-261.

CORDERO QuinZaCARA, Eduardo (2009): "Los principios y reglas que estructuran el ordenamiento jurídico chileno", en Revista Ius et Praxis, año 15, No 2, pp. 11-49.

Garrote Campillay, Emilio (2012): "Cosa Juzgada constitucional sui generis y su efecto en las sentencias del TC", en Revista Estudios Constitucionales (Año 10, No 2), pp. 391-42.

Gascón, Marina (1994): “Cuestiones sobre derogación”, en Doxa (15-16), pp. 845-859.

GUASTINI, Riccardo (2001): "Cinco observaciones sobre validez y derogación”, en Discusiones (No 2), pp. 59-63.

HenríqueZ Viñas, Miriam (2016): "Las fuentes del orden constitucional chileno", (Editorial Thomson Reuters, Santiago).

Henríquez Viñas, Miriam (2013): “¿Las normas derogadas pueden ser declaradas inaplicables por inconstitucionalidad? Comentario al fallo Rol No 1399 y 1469 
del Tribunal Constitucional", en Revista de Derecho Universidad Católica del Norte, año 18, No 1, pp. 301-306.

Nogueira Alcalá, Humberto (2010): "La sentencia del Tribunal Constitucional en Chile: análisis y reflexiones jurídicas", en Revista Estudios Constitucionales (Año 8, No 1), pp. 79-116.

NúNez Poblete, Manuel (2011): "Se acata pero no se cumple. Los efectos de la inaplicabilidad en el caso por no pago del bono por desempeño institucional. Gómez Montoya con Corporación Administrativa del Poder Judicial”, en Sentencias Destacadas, pp. 153-171.

NúNez Poblete, Manuel (2012): "Los efectos de las sentencias en el proceso de inaplicabilidad en Chile: examen a un quinquenio de la reforma constitucional”, en Revista Estudios Constitucionales (Año 10, No 1), pp. 15-64.

Rojas Chamaca, Julio (2013): "La derogación tácita de preceptos preconstitucionales por la jurisdicción ordinaria: Análisis jurisprudencial después de la reforma constitucional de 2005". (Editorial Metropolitana, Santiago).

Silva IrarRázAVAL, Luis (2010): "La derogación tácita por inconstitucionalidad. Comentario a la sentencia de casación dictada por la Corte Suprema, Sociedad Establecimiento Comercial Comarrico Ltda. con Héctor Enrique Alvear Villalobos, de 28 de septiembre de 2010, Rol No 1018-09”, en Revista de Derecho, Universidad Católica del Norte, (Año 18, No 1), pp. 307-315.

VEGA, Francisco y ZúNIIGA, Francisco (2006): "El nuevo recurso de inaplicabilidad por inconstitucionalidad ante el Tribunal Constitucional. Teoría y práctica", en Revista Estudios Constitucionales, (Año 4, No 2), pp. 135-174.

Verdugo Ramírez, Sergio (2008): "La declaración de inconstitucionalidad de las leyes como control represivo abstracto. Una especie de nulidad de Derecho Público atenuada en sus efectos", en Revista Actualidad Jurídica (No 18), pp. 247-297.

\section{Jurisprudencia de la Corte Suprema}

Corte Suprema. Rol No 35.236-2016, 30 de agosto de 2016.

Corte Suprema. Rol No 43.367-2016, 6 de octubre de 2016.

Corte Suprema. Rol No 44.989-2016, 6 de octubre de 2016.

\section{Jurisprudencia del Tribunal Constitucional}

Rol No 472, de 30 de agosto de 2006.

Rol No 784, de 20 de diciembre de 2007. 
Rol No 991, 29 de enero de 2009.

Rol No 1399 y 1469 acumuladas, de 4 de noviembre de 2010 .

Rol No 2341, de 14 de agosto de 2013.

Rol No 2647, de 23 de diciembre de 2014. 